\title{
Reconstruction of Cliché Image of Oriental Woman in Mohsin Hamid's Exit West
}

\author{
Kuğu Tekin \\ Assist. Prof. Dr., Atılım University, Faculty of Arts and Sciences, \\ Department of English Language and Literature \\ Zeynep Rana Turgut \\ PhD, Atılım University, Faculty of Arts and Sciences, \\ Department of English Language and Literature
}

\begin{abstract}
This paper attempts to hold a mirror to the existential struggle of an immigrant Muslim woman who is trying to survive on her journey to the west. Mohsin Hamid presents Nadia as one of the main characters in his 2017 novel Exit West. The paradox concerning Nadia is that while her preference for wearing a long black robe confirms the western misconstrued image of Muslim women, her actions, her view of the world, of life and of herself definitely refute the ingrained eastern notion of the suppressed, submissive, silenced Muslim woman. According to the dominant western view, oriental women are still under the strict control of the mechanisms of patriarchy. Among the control mechanisms of patriarchal order are traditions, norms, values and religion. However, Nadia does not fall into this western miscategorization of Muslim woman with her strong, rebellious character, and with her freethinking and insight. Indeed, it is Nadia, who safeguards, directs and in a sense, matures Saeed's-the other main character-rather timid and naïve personality. What is unexpected in the journey of these two characters is that the one who is need of identity reconstruction is not the female but the male character, for Nadia does already have a firmly constructed identity and she has no intention to transform either her outfit or her world view for the sake of integrating herself into the western culture. In brief, through the character of Nadia, Mohsin Hamid reconstructs the cliché image of oriental woman. In Exit West, Hamid reverses stereotyped gender roles by attributing his female character all the dominant personality traits attached to the male sex.
\end{abstract}

Keywords: Mohsin Hamid, Exit West, oriental woman cliché, reversed gender roles

\section{Introduction}

"There is no possible fight for someone deprived of an identity, no internal motivation for fighting, since although I can fight only with others, first I fight for myself"

Monique Wittig (1997, p. 269) 


\section{In an Unnamed Eastern City}

In Exit West, Mohsin Hamid presents Nadia and Saeed as his main characters who are trying to survive in a chaotic world where human existence seems to be merely coincidental. The beginning of the novel is set, in the unnamed city of an eastern country where political unrest is caused partly by the refugee flows from another unnamed neighbouring country and partly by the dissension between the government forces and the militants. To Michael Perfect (2019), "the names of the protagonists' city and their country are left blank, [...] to encourage readers to insert those of their own" (p. 190). Yet, to Shazia Sadaf (2020), the unnamed country is "quite identifiable as Pakistan, and the unspecified militants as the Taliban" (p. 639). At the onset, the author introduces the fragile atmosphere of the city and the encounter of his two protagonists as follows:

In a city swollen by refugees but still mostly at peace, or at least not yet openly at war, a young man met a young woman in a classroom. [...] His name was Saeed and her name was Nadia and he had a beard, not a full beard, [...], and she was always clad from the tips of her toes to the bottom of her jugular notch in a black robe. Back then people continued to enjoy the luxury of wearing more or less what they wanted to wear, clothing and hair wise, within certain bounds of course, and so these choices meant something. (Hamid, 2017, p. 1)

Nadia and Saeed meet in an evening class and a sudden intimacy grows between the two while the split between the militants and the present government deepens. Saeed is the only child of his parents and he still enjoys living with them. His father is a university professor and his mother is a retired schoolteacher. Ironically, Saeed and his well-read, liberal and moderate parents appear to be more conservative compared to Nadia who wears a black robe, giving the impression that she is a pious practising Muslim woman. Yet, she is riding a motorcycle and inside her black robe, she is wearing jeans and T-shirts. To Saeed's surprise, as she mounts her motorcycle, she puts on her head a helmet instead of a black cloth. Indeed, Nadia might be deemed a disbeliever for the black robe functions as a shield protecting her against possible sexual assaults as well as the various sanctions of religious patriarchy. She uses her religious attire as a mirror whereby, just like Perseus holding his shield against the deadly gaze of Medusa, she reflects upon eastern and western viewers their respective prejudices: while eastern viewers see a "properly" Muslim woman who is bound by tradition, western viewers perceive a woman oppressed by religious patriarchy; in truth, fitting neither of these two stereotypes, Nadia manages to navigate in life as a pragmatic survivor. When Saeed asks the frequency of her prayers, Nadia frankly and, even harshly, says that she does not pray at all. Since Saeed could not match Nadia's conservative appearance, her black robe, with her ideas about praying, he dares to ask a few days later: "'If you don't pray,' he said, lowering his voice, 'why do you wear it?' [...] She smiled. [...] 'So men don't fuck with me' she said" (Hamid, 2017, p. 16).

After finishing university, Nadia cuts off all her ties with the strictly religious members of her family when she announces that she will live on her own. To the tradition bound members of her family, the idea of a young single woman living alone without a male protector (a father or a husband) is definitely unacceptable. Indeed, since childhood, Nadia's curious character, her disrespectful demeanour and continual questioning of "unquestionable" religious issues have been not only infuriating but intimidating her father. So as to lead the life of a true free spirit, Nadia discards her father, mother and sister without hesitation, and thereafter, neither her family members nor she herself attempt to repair the broken ties between them, despite the 
feeling of regret that would follow all the four throughout their lives. Obviously, such a rebellious figure like Nadia, a young woman who refuses to conform to the coercive paradigms of patriarchy, would take the risk of forsaking her family. Nadia's family appears to be the smallest unit of a patriarchal society that is run by a patriarchal state. According to Kate Millett (2000), the family, society and the state are interrelated institutions and had there been a lack of cooperation between them, a collapse in all the three would have been inevitable (p. 33). In such patriarchal societies, the father is given the role of the head of the family; all family members should obey his absolute authority; that authority is also empowered by religious discourse so as to leave no room to any split in the family. In the case of Exit West, Nadia causes the break in the patriarchal family structure by renting a room to live as an independent woman; indeed, in order to rent the flat, Nadia lies that she herself is a widow just like the landlady. Consequently, Nadia puts a number of strategies into practice to tackle possible troubles threatening a single woman who relies on her instincts to survive in a chaotic city. Being a passionate follower of individual freedom, Nadia hides not just her body but also her free spirit under the black robe as she sets out on her long journey toward physical and mental liberation. Nadia's survival tactics at the beginning of her solitary life surrounded by an oppressive male dominated society read as follows:

Nadia's experiences during her first months as a single woman living on her own did, in some moments, equal or even surpass the loathsomeness and dangerousness that her family warned her about. But she had a job at an insurance company, and she was determined to survive, and so she did. She secured a room of her own [...] and [...] a circle of acquaintances among the city's free spirits, and a connection to a discreet and nonjudgmental gynaecologist. She learned how to dress for self-protection, how best to deal with aggressive men and with the [aggressive] police [...] and always to trust her instincts about situations to avoid or to exit immediately. (Hamid, 2017, pp. 18-19)

The quotation suggests that determination or having a daring personality and economic independence would not suffice to survive in such a misogynistic society. One instance displaying men's ferocious prejudiced attitude towards women in the city occurs when Nadia does not respond to the greeting of a man while the two stop at the red-light of an intersection. Nadia is on her motorcycle and the "burly man" is on his "tired-looking scooter" (Hamid, 2017, p. 39). In fact, the man's furious roar echoes centuries-long ingrained animosity reminding woman of her inferior status in the eastern social strata:

[He] began to swear at her, saying only a whore would drive a motorcycle, didn't she know it was obscene for a woman to straddle a bike in that way, had she ever seen anyone else doing it, who did she think she was, and swearing with such ferocity that she thought he might attack her, as she stood her ground, looking at him, visor down, heart pounding, but with her grip firm on clutch and throttle, her hands ready to speed her away, faster than he could follow [...]. (Hamid, 2017, p. 39)

Prior to her exit to the west, Nadia transgresses almost all the man-made prohibitive borders that are drawn to keep women under the strict control of the religious patriarchal society. Having secured a job at the insurance company and thus economic independence, Nadia starts enjoying her newly gained freedom; she has a brief affair with an underground musician who helps her to get rid of, what Nadia calls, "the weight of her virginity" (Hamid, 2017, p.31). In Nadia's eyes, this relationship appears to be physical, even experimental, rather than emotional. In a sense, she is exploring the nature of her sexuality albeit secretly. Another 
instance of border violation is that Nadia is the one who orders psychedelic mushrooms through social media to enliven her first intimate moments with Saeed. It is through their phones and social media accounts that Nadia and Saeed come into contact with the happenings in the outside world that are otherwise invisible to them. In other words, the fibre optic cables of the internet broaden the couple's horizons and open up to them "an invisible world, as if by magic, a world that was all around them, and also nowhere, transporting to the places distant and near, and to places that had never been and would never be" (Hamid, 2017, p. 35). Obviously, the digital technology of the twenty-first century challenges all sorts of geographical and physical boundaries and allows trespassers to access-either in the virtual or in the corporeal form-any piece of land they would like to set foot on.

As two sensitive young people, Nadia and Saeed start to feel much more insecure and restless due to the ongoing violence in the streets of the unnamed city. Especially, after Saeed's mother's tragic death on account of a stray bullet, Nadia moves to Saeed's apartment. Saeed and Nadia do their best to console Saeed's grieving father. On realising that what awaits them in the city is nothing but a dystopic future and ultimately death, Nadia and Saeed decide to leave their country together with Saeed's old father. Nevertheless, Saeed's father refuses to go with them for he knows he could not leave his past behind and make a new beginning elsewhere in the globe. The night before the couple's departure, Saeed's father talks to Nadia and entrusts her Saeed's life. The father wants Nadia to promise him that she must stand by Saeed's side through to safety, and that she should never leave him alone until the danger is over. The irony here is that in such a matter of life and death, the father entrusts Nadia with his only son's life; however, in a patriarchal society, the reverse is expected to happen for woman is regarded as weak, incapable and passive. Yet, as the epigraph taken from Wittig suggests, Nadia is a born fighter, and as a wise reader of human nature, Saeed's father sees her potential, her strong identity and that she will fight not just for herself but also for Saeed. In her article Sadaf (2020) explains the meanings of the names Nadia and Saeed: "The name Nadia means 'hope' and a 'caller.' Saeed means 'fortunate' and 'lucky'" (p. 644). As is understood, Saeed is lucky to be safeguarded by Nadia-hope- in his tough journey to the west.

In Sexual Politics, Millett (2000) asserts that the socialization of male and female sexes in patriarchal polities is designed "with regard to temperament, role and status" (p. 26). According to Millett (2000), human temperament is based on stereotyped sex categorization ("masculine" and "feminine"), and the defining traits of male personality are aggression, intelligence, force and efficacy; female is associated with passivity, ignorance, docility, virtue and ineffectuality. The second factor is sex role that "assigns domestic service and attendance upon infants to the female, the rest of human achievement, interest, and ambition to the male" (p. 26). As to status, the majority confirms to assign superior status to the male and an inferior one to the female. Millett (2000) states that temperament is psychological; role is social and status is political; "[Y] et their interdependence is unquestionable and they form a chain. Those awarded higher status tend to adopt roles of mastery, largely because they are first encouraged to develop temperaments of dominance" (p. 26). In the case of Exit West, however, it is observed that Nadia belies all the prejudiced, stereotyped, patriarchal view of woman with her mindset, personality traits and behaviours. It is Nadia, not Saeed, who possesses all the traits that her particular eastern society assigns to men, and Saeed's father is the only person to recognise her exclusive nonconformist character. 


\section{On the Threshold of West: The Greek Island of Mykonos}

Nadia and Saeed flee the country, pass through a number of magical doors, and arrive at their first destination, the Greek island of Mykonos. During their mysterious journey, Nadia is the one to take the initiative; she "cradles" and calms down the worried, sorrowful, weak Saeed as they find themselves in a public bathroom on Mykonos. The first refugee camp the couple see on this European land is a medley of races, cultures, languages and beliefs from all over the world. Nadia and Saeed feel as if a lessened version of a greater globalised world is extending in front of their eyes:

[T] hey saw [...] a refugee camp, with hundreds of tents and lean-tos and people of many colors and hues but mostly falling within a band of brown that ranged from dark chocolate to milky tea-and these people were [...] speaking in a cacophony that was the languages of the world, what one might hear if one were a communications satellite, .... (Hamid, 2017, p. 100)

Mykonos is the place where Nadia detects a change in Saeed's temperament for the first time. She sees bitterness on his face when she tries to kiss him. She thinks, "a bitter Saeed would not be Saeed at all" (Hamid, 2017, pp. 102-103).

The couple is swindled by a fellow countryman, one of Saeed's acquaintances, who promises the two that he will provide them a safe passage to Sweden. In fact, the man is a human trafficker, and after getting his charge, he disappears never to be seen again. Although both Nadia and Saeed are aware of the abundant number of frauds swindling immigrants on the route to the west, Saeed prefers to believe that something wrong might have happened to the trafficker; and for a while, he even prays for his safe return. This act of swindling is another incidence displaying the sharp contrast between the two protagonists' personalities in that while the pragmatic, reasonable Nadia accepts it as an ordinary and predictable act of human opportunism, the naïve, emotional Saeed could not stand the idea of being swindled by a fellow countryman. Nadia meets a young volunteer girl who is working at a clinic. The bond established between the girl and Nadia opens up a new magical door that ends the couple's Mykonos adventure and allows them to experience a new one in London.

\section{London: The Couple's Second Destination}

During their London experience, the couple gradually move apart because both start to act according to their individual will which leads them to make their own independent choices. The London house where Nadia and Saeed take shelter is populated by a group of diverse nationals. To Eva Rusk Knudsen and Ulla Rahbek (2021), "[w]hile Saeed feels anxious and easily intimidated in the company of unfamiliar people, Nadia is unafraid and worldly" (p. 5). It is noteworthy that the more Nadia moves towards west the more she feels secure and liberated; her optimistic extrovert nature enables her to contact with new people easily. For instance, her acceptance by the Nigerian community living in Palace Gardens Terrace satisfies Nadia profoundly because that particular group provides her, as Amanda Lagji (2019) suggests, a heterogeneous space, which is devoid of restrictive nationalistic concerns (p. 227), a liberating space where she can gain new perspectives, new ways of seeing things, which she considers an achievement. However, being harassed by the most aggressive members of the Nigerians, the terrified Saeed "huddle[s] in a corner" of his room just like a little child waiting to be saved by a motherly figure. Due to being exposed to such hostile attitudes, Saeed does not cherish any desire to know a new culture or new people like Nadia; thus, instead of trying to adapt himself to the circumstances of British culture, Saeed is drawn to his fellow country 
folk, a group of Muslim immigrants who are leading a commune life in a nearby housing complex. That house becomes the only place where Saeed feels both physically and spiritually united. Being unable to fill in the void within him, Saeed tries to persuade Nadia to move to the house where his folks reside. The conversations Saeed holds with the leader of this group help him escape his nostalgic and melancholic mood to a certain extent. Saeed believes he could at least develop a sense of belonging if only he could become a part of his native community. However, the Muslim group's rule dictating couples to sleep separately in different rooms irritates Nadia and she rejects Saeed's offer of moving to that dwelling instantly. The reason why Nadia rejects Saeed's offer is that she neither longs for nor feels connected to her people as she thinks "[t]hey are not like [her]" [Hamid, 2017, p.149).

Nadia and Saeed see a fox wandering in the garden of the London house at two successive nights. It is clear that Hamid's placement of a fox that is observing its alien surrounding discreetly is not coincidental. The author's intention might be drawing parallels between the craftiness of the little fox with that of Nadia, for the fox craftily trespasses the borders of its natural environment, gets access to the unnatural urban space and survives unharmed without being caught. Just like the fox, Nadia migrates from her native city, trespasses a number of geographical borders and craftily survives the prejudices, suspicions and hostilities she encounters in all the foreign localities. And while doing all of these, she is actively protecting Saeed against possible threats awaiting them outside in this new environment. In fact, Nadia's instinct to protect Saeed against internal and external threats is another proof of reversed gender roles in that the couple's native patriarchal society posits the male "as the essential [the One] as opposed to [the female] the other, the inessential, the object" (Beauvoir, 2010 , p. 26). Though Saeed never assumes the role of "the One," "the essential" neither in his native society nor in the west, he is appalled when he falls into the category of "the Other" in a foreign context. To Beauvoir (2010), the native travelling abroad "is shocked to realize that in neighbouring countries locals view him as a foreigner; ..." (p. 27). Likewise, Saeed is otherised by both Nigerians and British nativists due to his alien status in London. Therefore, when the nativist backlash against immigrants exacerbates, Nadia and Saeed move to a labour camp outside London.

During their sojourn in the camp, Nadia and Saeed begin to move away from each other not physically but emotionally. Nadia is no longer attracted to Saeed and she even starts to see him like the brother she never had. To Sadaf (2020), the characters' identities undergo a radical change each time they pass through a magical door. Sadaf likens this transformation to a rebirth, and that is likely to be the reason of the change in the nature of their relationship:

Nadia and Saeed's metaphoric twin birth through the door changes their identity and, as a result, their relationship. Having drawn comfort from each other's closeness in the past and finding solace in their similarity based on the geography of their initial nascence, they slowly drift apart in time, and form their own new lives, as their love changes to something like a fondness between siblings. (p. 642)

Furthermore, another significant reason behind this emotional change is Nadia's awareness of her sexual identity. Having dreamt of the girl in Mykonos, Nadia discovers that her body is fraught with some new erotic impulses. In addition, Hamid's apt insertion of three-page long vignettes after each chapter, except for the final chapter, draws attention to the change in Nadia's sexual preference. The vignettes to which Claire Chambers (2019) refers as "cut-piece scenes," (p. 237) present a number of similar migration stories simultaneously occurring 
throughout the globe. These vignettes may be considered indicators of future happenings in Exit West. For instance, chapter nine features two old men, one being Dutch and the other a Brazilian; while the two men are kissing each other on a balcony in Amsterdam, a war photographer takes a photograph of them. Yet, she deletes this photograph later for she realises that this is an inconsiderate, disrespectful behaviour, an invasion of the two men's privacy (Hamid, 2017, p. 175). In fact, this vignette foreshadows Nadia's future lesbian identity, which may be regarded as a reaction against patriarchy's imposition of heterosexuality on both sexes. In "Imitation and Gender Insubordination" Judith Butler (1997) claims "compulsory heterosexuality sets itself up as the original, the true, the authentic" (p. 306) because in society only the norms of heterosexuality define the roles of man and woman. It is commonly believed that heterosexuality is natural or normal and homosexuality is a kind of "miming" the norm. For the sake of legitimizing its status as the original and normal, heterosexuality labels homosexuality abnormal and "miming." Thus, the war photographer deletes the kissing scene considering that her particular society could marginalise or "otherize" the two men on account of her photograph. Indeed, Butler (1997) asserts that it is heterosexuality that is not original: "The reality of heterosexual identities is performatively constituted through an imitation that sets itself up as the origin and the ground of all imitations" (p. 307). Hamid creates Nadia as a free spirit, a person who never mimics but is followed. By preferring a lesbian identity, Nadia rejects the ideological, economic and political power of man as Wittig (1997) claims:

The refusal to become heterosexual always meant to refuse to become a man or a woman, consciously or not. For a lesbian this goes further than the refusal of the role "woman." It is the refusal of the economic, ideological, and political power of man. (p. 267)

Saeed's attitude towards Nadia also changes, especially after hearing the news of his father's death. He devotes his labour camp days to hardworking and praying as the emotional gap between the couple widens.

\section{The Final Destination: Marin, San Francisco}

It is observed that Nadia is the one to decide where and when to go since the beginning of their journey, and her last decision is going to Marin, San Francisco, hoping "to be able to rekindle their relationship, to reconnect with their relationship" (Hamid, 2017, p. 193); however, it gets worse. Saeed becomes "more melancholic than he [has] been before, understandably, and also more quiet and devout" (Hamid, 2017, p. 193) because the further west he goes, the farther he is moving away from his native country, and entering a culture he could not adopt makes him a quiet and passive introvert. In fact, turning into passive victims is an expected characteristic of men who are in the asylum seeking process. As Deirdre Conlon (2011) suggests male figures in refugee position display some of the character traits attributed to women: "[A]sylum seekers' encounters with waiting belie the masculinist hue with which they are cast en route to the global North as they are re-inscribed with feminized codings of stasis and passivity" (p. 357). Likewise, Saeed falls into a state of numbness until he meets the preacher's daughter. In a sense, Saeed's relationship with the preacher's daughter relieves Nadia; she believes that her mission as Saeed's protector is accomplished. Thus, both sides agree on parting with complacency in this "new city," Marin. In Perfect's (2019) words: "Having begun in an old city that was being destroyed, their relationship ends in a new city that is being built. In a sense, Nadia and Saeed migrate away from each other" (p. 192). Hamid's last destination, Marin, adds an optimistic tone to the migration story. Obviously, the author's choice of Marin is not 
coincidental in that Marin provides migrants from all around the world with a heterogeneous space where diverse histories, cultures, races, languages and beliefs live and express themselves freely.

It is noteworthy that Nadia stubbornly keeps wearing her black robe throughout her journey. Nadia's insistence on wearing the black robe annoys Saeed for he thinks, she is no longer in her native country, and she does not even pray. In Saeed's eyes, Nadia's long black robe gives the misleading impression that she is a properly practising pious Muslim woman, and since he knows that it is not so, he finds her attire meaningless and hypocritical. He thinks that Nadia is betraying her indigenous culture in every way:

But it was inexplicable that she continued to wear her black robe, and grated on [Saeed] a bit, for she did not pray, and she avoided speaking, and she avoided their people, and sometimes he wanted to shout, well take it off then.... (Hamid, 2017, p. 187)

Saeed fails to understand the actual reason behind Nadia's insistence on the black robe. She wears it not to display her commitment to a particular religion or a culture but to protect her integrity, her freedom in both hemispheres of the globe. Yet, both westerners and easterners misjudge her attire. The author's continual emphasis on the black robe draws attention to the contradiction between the identities of the two protagonists. As Knudsen and Rahbek (2021) note,

Nadia is a self-determining woman curious about life and always welcoming newness. Her densely signified black robe is re-signified as a means of safeguarding her personal space. [...] [I]t is a self-customized emblem of her personality, one which also grants her operational integrity in public contexts. (pp. 5-6)

In Marin, Nadia's black robe is seen as a religious symbol and even sometimes associated with terrorism. Her attire stimulates western Islamophobia. Thus, the majority of people with whom Nadia contacts in Marin regard her as a potential threat. For instance, to Nadia's female co-workers in the food cooperative, "her black robe was thought by many to be off-putting, or self-segregating, or in any case vaguely menacing, and so few of her colleagues had really reached out to her..." (Hamid, 2017, pp. 213-14). However, after witnessing Nadia's "mettle in the face of [real] danger" (Hamid, 2017, p. 214), or Nadia's silent resistance against the "paleskinned tattooed man" (Hamid, 2017, p. 214), with a pistol, the workers realise who the real threat is and "who is threatened" (Hamid, 2017, p. 214). Thus, it is understood that the black robe does not function as an identity marker but as a protective shield tightly held by Nadia against socially constructed western and eastern clichés concerning woman. As Sadaf (2020) argues,

Having it on and keeping it on [...] as a sign of her agency, Nadia finds a new confidence in her identity and refuses to be labelled immutably by her choice of clothing. In other words, she keeps her robe on but liberates her identity to new experiences. (p. 643)

\section{Conclusion}

Half a century later when Nadia meets Saeed in the city of their birth, she has the same attire on and she is described as an "old woman in her black robe" (Hamid, 2017, p. 228). Throughout her life, Nadia's black robe caused her many troubles; sometimes she is regarded as a terrorist threat; sometimes as an oppressed, silenced Muslim woman; and sometimes she is criticised by her fellow country people for being alienated from her specific religious belief and the 
conventions of her indigenous culture. Nevertheless, Nadia keeps her black robe on so as to proceed freely on her self-drawn path. Here, one cannot help recalling Rumi's comment on human nature. Rumi establishes a parallel between books and human beings and says that in order to understand the true character of a person one should focus not on the cover but on the content of the book because a gilded cover might be misleading. In the case of Exit West, Nadia's black robe is her cover; and one should definitely concentrate on her mindscape in order to see and understand the free spirit lying under the black fabric.

Mohsin Hamid's Exit West recounts an immigrant couple's journey to the west. As the couple move toward west, Saeed turns out to be a passive, silent, isolated figure, while Nadia becomes more active and liberated. To Liliana Naydan (2019), "while Nadia feels a sense of liberation in leaving the gender-based oppression that defines her experiences in the predominantly Muslim unnamed city, [...] Saeed tends to long for the sort of cultural and religious community he had prior to migration" (p. 439). In Exit West, Hamid reverses, and thus, reconstructs stereotypical gender roles that are defined by the norms of patriarchy. Hamid's female protagonist deconstructs the cliché image of the Muslim woman with her courage, her sexual identity and her liberating views of herself and of the world on the move.

A deeper understanding of this stereotypical representation of the female Muslim immigrant may be achieved-in a series of comparative analyses-by, on the one hand, tracing the historical evolution of the stereotype in the works of authors from different decades, and on the other, by juxtaposing variations in the representation of the said figure in the works of contemporary authors.

\section{References}

[1] Beauvoir, de Simone. (2010). The second sex. Trans. C. Borde \& S. MalovanyChevallier, New York: Vintage Book.

[2] Butler, J. (1997). Imitation and gender insubordination, The second wave: A reader in feminist theory. In L. Nicholson (Ed), New York: Routledge.

[3] Chambers, C. (2019). Making sense of contemporary British Muslim novels. UK: Palgrave Macmillan.

[4] Conlon, D. (2011). Waiting: feminist perspectives on the spacings/timings of migrant (immobility), Gender, Place\&Culture, 18:3, 353-360, DOI: 10.1080/0966369X.2011.566320.

[5] Hamid, M. (2017). Exit West. UK: Penguin Books.

[6] Knudsen, E. \& U. Rahbek. (2021). Radical hopefulness in Mohsin Hamid's map of the world: A reading of Exit West, Journal of Postcolonial Writing, 1-13, DOI: 10.1080/17449855.2021.1889641

[7] Lagji, A. (2019). Waiting in motion: mapping postcolonial fiction, new mobilities, and migration through Mohsin Hamid's Exit West, Mobilities 14:2, 218-232, DOI: 10.1080/17450101.2018.1533684.

[8] Millett, K. (2000). Sexual politics. New York: University of Illinois Press.

[9] Naydan, L. (2019). Digital screens and national divides in Mohsin Hamid's Exit West, Studies in the Novel, 51:3, 433-451. DOI:10.1353/sdn.2019.0048.

[10] Perfect, M. (2019). Black holes in the fabric of the nation: refugees in Mohsin Hamid's Exit West, Journal for Cultural Research, 23:2, 187-201, DOI: 10.1080/14797585.2019.1665896. 
[11] Preston, A., (Interviewer), \& Hamid, M., (Interviewee). (2018, August 11). The Guardian. Retrieved from https://www.theguardian.com/books/2018/aug/11/mohsin-hamid-exit-westinterview

[12] Sadaf, S. (2020). We are all migrants through time: History and geography in Mohsin Hamid's Exit West, Journal of Postcolonial Writing, 56:5, 636-647, DOI: $10.1080 / 17449855.2020 .1820667$.

[13] Wittig, M. (1997). One is not born a woman, The second wave: A reader in feminist theory. In L. Nicholson (Ed), New York: Routledge. 